\title{
SIMULAÇÃO E ANÁLISE DO PROCESSO DE TRILHA E SEPARAÇÃO MECÂNICA DO MILHO-PIPOCA
}

\author{
Cristiano Márcio Alves de Souza ${ }^{1}$, Francisco de Assis de Carvalho Pinto ${ }^{2}$, \\ Evandro Chartuni Mantovani ${ }^{3}$ e Daniel Marçal de Queiroz ${ }^{4}$
}

\begin{abstract}
RESUMO
O objetivo deste trabalho foi avaliar o efeito da trilha mecânica na qualidade do milho-pipoca e desenvolver um programa computacional para simulação do processo de trilha numa máquina com mecanismo de cilindro de barras e côncavo. Os testes experimentais foram realizados utilizando-se duas variedades de milho-pipoca, Zélia e CMS-43, combinadas com três rotações do cilindro trilhador, 500, 600 e 700rpm. Analisou-se a capacidade de expansão e a eficiência de separação do côncavo, em que a variedade Zélia apresentou maior capacidade de expansão e maior porcentagem de injúria em relação à CMS-43. O erro na determinação da eficiência de separação do côncavo pelo modelo matemático implementado foi de 3,96\%, considerado satisfatório para aplicações em engenharia.
\end{abstract}

Palavras-chave: colheita, eficiência de separação do côncavo, danos mecânicos

\section{SIMULATION AND ANALYSIS OF MECHANICAL THRESHING AND SEPARATION PROCESS OF POPCORN}

\begin{abstract}
The objective of this study was to evaluate the effect of mechanical threshing in the popcorn quality and to develop software for simulating the threshing process of a machine with a bar cylinder and concave mechanism. The experimental tests were done with two varieties of popcorn, the Zélia and the CMS-43, and with three speeds for the threshing cylinder, 500, 600 e 700rpm. The expansion volume and the concave separation efficiency were analyzed. The Zélia variety presented greater expansion volume and greater mechanical damage compared to the CMS-43 variety. The error of the developed software in predicting the concave separation efficiency was 3.96 percent, that was considered to be satisfactory for engineering applications.
\end{abstract}

Key words: harvest, separation efficiency, mechanical damage

\section{INTRODUÇÃO}

A operação da colheita manual, da mesma forma que os demais processos manuais, é de baixa capacidade operacional e, portanto, viável economicamente apenas em propriedades onde a finalidade principal da produção é a subsistência do agricultor e de sua família.

A redução do número de pessoas trabalhando na agricultura e a necessidade de maior produção de alimentos, devido ao aumento da população, têm gerado uma crescente demanda de

\footnotetext{
${ }^{1}$ Graduando em Engenharia Agrícola, Bolsista da FAPEMIG, Departamento de Engenharia Agrícola da UFV, Campus da UFV, Viçosa, MG, CEP 36571-000, fone: (031)899-1882. E-mail: e32247@alunos.ufv.br

2 Prof., MS, Departamento de Engenharia Agrícola da UFV. E-mail: facpinto@mail.ufv.br

${ }^{3}$ Pesquisador, Ph.D., Centro Nacional de Pesquisa do Milho e Sorgo, EMBRAPA, Sete Lagoas, MG, fone: (031)779-1105.

E-mail: evandro@cnpms.embrapa.br

${ }^{4}$ Prof., Ph.D., Departamento de Engenharia Agrícola da UFV. E-mail: queiroz@mail.ufv.br
} 
se mecanizar as etapas de produção agrícola. No caso específico da colheita, existe um fator a mais a ser considerado pelos agentes envolvidos: a qualidade do produto colhido.

A colheita de cereais envolve as etapas de corte, alimentação, trilha, separação e limpeza do produto. A trilha, se mal conduzida, pode ser responsável por significativa perda de produto e, segundo Carvalho \& Nakagawa (1980) trata-se de uma das mais importantes fontes de danificação dos grãos. Para o milho-pipoca, esse problema é mais complexo, tendo-se em vista que, além das danificações visíveis, ocorrem também danificações microscópicas, podendo comprometer a capacidade de expansão do milho; esta capacidade é a principal característica do milho-pipoca, pois ela é definida pela relação existente entre o peso das sementes e o volume de pipocas; costuma-se usar, também, a relação entre o volume de sementes e o de pipocas. Quanto maior for a capacidade de expansão, maior valor comercial terá a variedade, pois esta característica está associada à maciez da pipoca. Segundo Zinsly \& Machado (1978) a umidade ideal para o pipocamento varia em função do tamanho da semente mas, de maneira geral, os melhores resultados são obtidos em torno de $12 \%$ b.u., sendo que o pipocamento se inicia pouco depois que a temperatura do grão atinge $180^{\circ} \mathrm{C}$.

O milho-pipoca é utilizado quase que exclusivamente para o consumo humano; sua capacidade de expansão está relacionada à resistência do pericarpo, associado à presença no grão de óleo e umidade (Zinsly \& Machado, 1978). As fibras de celulose são densamente trançadas, sendo grande a resistência mecânica exercida sobre a película, permitindo que o calor chegue ao amido antes que a casca se queime; com o calor, o amido se expande, aumentando gradativamente a pressão interna do grão até que ocorra a explosão (Silva, 1993). Desta forma, se houver comprometimento da integridade do pericarpo, ocorre uma "fuga" da pressão interna impedindo, assim, a expansão do milho-pipoca.

White et al. (1981) citam a carência de informação a respeito das características do milho-pipoca, sendo que a maioria dessas informações diz respeito ao efeito da secagem na qualidade do mesmo, porém com o aumento da demanda deste produto no mercado brasileiro, com conseqüente aumento de área plantada (Coopercitrus, 1993) surge a necessidade de novos trabalhos, principalmente utilizando as novas variedades e explorando o efeito da colheita mecânica na qualidade do milho-pipoca.

A simulação de processos através do desenvolvimento de modelos matemáticos e programas computacionais, tem-se mostrado ser uma ferramenta de grande utilidade no auxílio ao projeto de novas máquinas ou no aprimoramento das já existentes, permitindo a diminuição de custos e tempo.

Huynh et al. (1982) desenvolveram um modelo matemático para simular a trilha de trigo em um sistema convencional de cilindro de barras e côncavo; nele, a debulha foi considerada um processo randômico, podendo este modelo ser adaptado para outros produtos ou outros tipos de trilha e o resultado obtido é a eficiência de separação do côncavo que, segundo Norris \& Wall (1986) é definida como a relação entre os grãos debulhados que passaram pela grade do côncavo e os grãos que entraram na máquina. A eficiência de separação do côncavo é função da velocidade periférica do cilindro trilhador, da abertura entre o cilindro trilhador e o côncavo, do estado das condições da cultura (umidade e maturação) e da taxa de alimentação da máquina, sendo a velocidade do cilindro trilhador o mais importante parâmetro com relação à perda de sementes por deficiência de debulha e injúrias causadas aos grãos (Kepner et al., 1972).

Este trabalho objetivou o estudo do efeito da trilha mecânica na qualidade do milho-pipoca e o desenvolvimento de um programa computacional para a simulação de uma trilhadora convencional, com base no modelo proposto por Huynh et al. (1982).

\section{MATERIAL E MÉTODOS}

O trabalho foi conduzido nos Laboratórios de Microcomputadores e de Mecanização Agrícola do Centro Nacional de Pesquisa do Milho e Sorgo (CNPMS-EMBRAPA Sete Lagoas) e no Departamento de Engenharia Agrícola da Universidade Federal de Viçosa.

O produto utilizado foi o milho-pipoca, variedades Zélia e CMS-43, provenientes de campo experimental do CNPMSEMBRAPA, Sete Lagoas MG. As espigas foram colhidas manualmente em quantidades suficientes para todos os testes, realizados no dia seguinte.

Para se estudar o efeito da trilha na capacidade de expansão do milho-pipoca, montou-se um experimento em esquema fatorial $2 \times 3$, com duas variedades e três rotações do cilindro trilhador, instalado segundo o delineamento inteiramente casualizado, com três repetições. Para validar o programa computacional desenvolvido, além dos dados provenientes dos testes de qualidade, foram realizados outros testes com diferentes taxas de alimentação da colhedora, com três repetições cada um.

\section{Desenvolvimento do modelo matemático para determinação da eficiência de separação do côncavo}

O modelo foi desenvolvido com base no proposto por Huynh et al. (1982) para trigo; considerou-se que, para ocorrer a separação do produto no processo de trilha, deve-se seguir a sequiência abaixo:

Evento 1 - separação dos grãos do sabugo pela ação da trilha Evento 2 - migração dos grãos através da camada de palha Evento 3 - passagem dos grãos através da grade côncava.

As principais hipóteses usadas no desenvolvimento do modelo probabilístico baseiam-se nas seguintes teorias:

1) qualquer grão está igualmente apto a ser debulhado em qualquer tempo;

2) qualquer grão está igualmente apto a alcançar a superfície da grade côncava em qualquer tempo;

3) qualquer grão está igualmente apto a passar através da grade côncava em qualquer tempo.

A lei de probabilidade utilizada como base para o desenvolvimento do modelo para a simulação do processo de trilha, foi a densidade de probabilidade exponencial:

$$
\mathrm{f}_{\mathrm{i}}(\mathrm{t})=\frac{1}{\tau_{\mathrm{i}}} \mathrm{e}^{\left(\frac{-\mathrm{t}}{\tau_{\mathrm{i}}}\right)}
$$

em que:

t - tempo para a ocorrência da debulha de um grão

$1 / \tau_{\mathrm{i}}$ - taxa média da ocorrência da debulha do grão no tempo decorrido entre a entrada do produto na máquina e a sua debulha.

A Equação 1 representa a probabilidade de ocorrer a trilha. No modelo matemático desenvolvido, a camada do produto entre o côncavo e o cilindro trilhador foi dividida em várias 
subcamadas e o processo de trilha foi dividido em três sucessivos e independentes eventos.

\section{Evento $1\left(\lambda_{1}\right) \rightarrow$ Ocorrência da trilha}

Para simular o processo de debulha, considerou-se que a velocidade de separação dos grãos de suas ligaduras é proporcional à energia despendida para a colheita e à transmissibilidade desta energia, através da densidade da camada de palha-grão. A energia despendida é considerada proporcional à energia motriz das barras do cilindro, e a transmissibilidade da energia está relacionada ao inverso da abertura entre cilindro e côncavo. Desta maneira, foi utilizada a seguinte relação para o cálculo de $\lambda_{1}$ :

em que:

$$
\lambda_{1}=k_{t} \frac{\rho V_{t}^{2} W D}{Q C}
$$

$\lambda_{1}$ - taxa de ocorrência do evento 1, grãos por segundo

$k t$ - constante de debulha

$\rho$ - densidade livre do material que não é grão

$\mathrm{V}_{\mathrm{t}}$ - velocidade periférica das barras do cilindro

W - largura do cilindro

D - diâmetro do cilindro trilhador

Q - taxa de alimentação do sistema de trilha

C - abertura média entre cilindro e côncavo.

\section{Evento $2\left(\lambda_{2}\right) \rightarrow$ Migração dos grãos separados através} da camada de palha-grão

Durante o tempo de residência no côncavo, os grãos soltos estão submetidos à força da gravidade e à aceleração centrífuga. A força deste movimento faz com que os grãos superem a resistência da palha e migrem para um raio maior. Para o cálculo da taxa de ocorrência do evento, utilizou-se a seguinte relação:

$$
\lambda_{2}^{j}=\frac{1}{\tau}
$$

em que:

$\lambda_{2}^{j}$ - taxa de ocorrência do evento 2 (grãos que alcançam o côncavo a partir de uma posição “j”, medida na direção radial do cilindro)

$\tau$ - tempo médio para o grão ultrapassar uma camada de palhagrão, de espessura $\delta$, até atingir o côncavo.

$\mathrm{O}$ valor de $\tau$ foi determinado pela seguinte expressão:

$$
\tau=K_{m} \sqrt{\frac{\varsigma}{g+\frac{2 V_{S}^{2}}{D}}}
$$

em que:

$\mathrm{Km}$ - constante de correção

g - aceleração da gravidade

$\mathrm{V}_{\mathrm{s}}$ - velocidade média de avanço da palha-grão na região de trilha

$\zeta$ - espessura da camada a partir da posição “j”.

A velocidade média de avanço da palha-grão na região de trilha pode ser determinada pela expressão abaixo:

em que:

$$
V_{s}=\frac{K_{f} V_{0}+K_{r} V_{t}}{2}
$$

$K_{f}$ e $K_{r}$ - fatores de deslizamento da esteira que alimenta o cilindro e barras do cilindro, respectivamente.
$V_{0}$ - velocidade da esteira que alimenta o cilindro.

\section{Evento $3\left(\lambda_{3}\right) \rightarrow$ Passagem dos grãos que atingem a grade côncava}

Para um grão que tenha passado através da camada de palha e esteja deslizando através da superfície do côncavo numa velocidade constante, é presumível, também, que ele passará através do côncavo se sua projeção sobre a superfície do côncavo for compatível. A relação utilizada no modelo para determinar $\lambda_{3}$ foi a seguinte:

$$
\lambda_{3}=\frac{V_{S}\left(a_{1}-a_{2}-d_{g}\right)\left(b_{1}-b_{2}-d_{g}\right)}{a_{1} b_{1}^{2}}
$$

em que:

$\lambda_{3}$ - taxa de ocorrência do evento 3

$a_{1}$ - distância entre as barras circulares do côncavo

$a_{2}$ - diâmetro das barras circulares do côncavo

$b_{1}$ - distância entre as barras retangulares do côncavo

$b_{2}$ - espessura das barras retangulares do côncavo

$d_{g}$ - diâmetro equivalente do grão.

Desta maneira, existe a probabilidade de ocorrerem a trilha do produto, a migração dos grãos através da camada de palha e a passagem dos grãos através do côncavo. A relação entre esta probabilidade, que fornece a eficiência de separação do sistema, usada para modelar o sistema de trilha e separação, foi:

$\eta_{T}=1-\frac{1}{m} \sum_{j=1}^{m} \frac{\lambda_{2}^{j} \lambda_{3}\left(\lambda_{2}^{j}-\lambda_{3}\right) e^{-\lambda_{1} t_{c}}+\lambda_{3} \lambda_{1}\left(\lambda_{3}-\lambda_{1}\right) e^{-\lambda_{2}^{j} t_{c}}+\lambda_{1} \lambda_{2}^{j}\left(\lambda_{1}-\lambda_{2}^{j}\right) e^{-\lambda_{3} t_{c}}}{\left(\lambda_{1}-\lambda_{2}^{j}\right)\left(\lambda_{2}^{j}-\lambda_{3}\right)\left(\lambda_{1}-\lambda_{3}\right)}$

em que:

$\eta_{\mathrm{T}}$ - eficiência de separação

m - número de camadas em que será dividida a camada de palha grão na região entre o cilindro e o côncavo, no sentido radial

$t_{c}$ - tempo de permanência dos grãos na região de debulha.

\section{Testes experimentais}

Os testes de trilha foram realizados em uma colhedora combinada para parcelas experimentais, marca Wintersteiger, modelo Nursermaster elite.

A máquina era alimentada por uma esteira de $13,87 \mathrm{~m}$ de comprimento, com velocidade de $0,58 \mathrm{~m} . \mathrm{s}^{-1}\left(2,08 \mathrm{~km} \cdot \mathrm{h}^{-1}\right)$. Para os testes de qualidade, as espigas eram colocadas na esteira, espaçadas $18 \mathrm{~cm}$, aproximadamente, num total de 155 espigas por teste. A duração de cada teste foi de uns 48 segundos, representando uma colheita de 38 e $33 \mathrm{~m}$ de linha, valores estes equivalentes a uma velocidade de $0,79 \mathrm{~m} . \mathrm{s}^{-1}\left(2,85 \mathrm{~km} \cdot \mathrm{h}^{-1}\right)$ e de $0,69 \mathrm{~m} \cdot \mathrm{s}^{-1}\left(2,47 \mathrm{~km} \cdot \mathrm{h}^{-1}\right)$ da colhedora para as duas variedades, respectivamente; os testes restantes foram realizados variandose a taxa de alimentação, enquanto para os de qualidade utilizaram-se as rotações de 500, 600 e 700rpm no cilindro trilhador, e os testes com diferentes taxas de alimentação foram realizados com uma velocidade angular de 500rpm no cilindro trilhador.

Para a validação do programa computacional foram determinados, em cada teste, a rotação do cilindro trilhador, a massa total do material que entrava na máquina, o tempo de duração, a densidade livre do produto, o tempo de deslocamento 
do produto na região de debulha, a umidade e a eficiência de separação do côncavo. Após cada teste, retiraram-se amostras para determinação da capacidade de expansão do milho-pipoca.

Após a realização de cada teste foram retiradas amostras no graneleiro da máquina; para a determinação da umidade, com o método em estufa a $105^{\circ} \mathrm{C}$ por $24 \mathrm{~h}$; já a taxa de alimentação foi obtida por meio da determinação da massa das espigas utilizadas em cada teste e da cronometragem do tempo gasto para a debulha do material; em seguida, determinou-se a densidade do produto com o auxílio de um recipiente de volume conhecido, enquanto certa quantidade do produto foi colocada dentro do recipiente, livremente, sem compactação; finalmente, foi determinado o peso do produto e sua densidade foi expressa em quilogramas por metro cúbico do recipiente.

O tempo de deslocamento do produto na região de debulha foi determinado cronometrando-se o tempo gasto pelo produto para deslocar-se da entrada à saída da região de debulha; a eficiência de separação do côncavo foi determinada colocando-se uma lona sob a peneira superior da colhedora, com o objetivo de obstruir a passagem dos grãos da peneira para o tanque graneleiro; assim, os grãos encontrados no tanque foram apenas aqueles separados na região de debulha e que alcançaram a grade do côncavo; o produto inicial que entrava na máquina, no tanque graneleiro, na lona sob a peneira e a perda, foi pesado.

Calculou-se a eficiência de separação do côncavo da seguinte forma:

$$
\eta_{T}=\frac{P_{1}}{P_{1}+P_{2}+P_{3}}
$$

em que:

$\mathrm{P}_{1}$ - peso do material separado no côncavo

$\mathrm{P}_{2}$ - peso do material encontrado sob a peneira

$\mathrm{P}_{3}$ - peso da perda.

Para a determinação dos danos mecânicos, de cada teste retiraram-se amostras de aproximadamente $200 \mathrm{~g}$ de grão no tanque graneleiro da máquina, para análise da qualidade e dos danos provenientes da colheita. Dessas amostras eram retirados e pesados os grãos com injúria para determinação da porcentagem de grãos danificados.

Para a obtenção da capacidade de expansão, utilizou-se uma pipoqueira elétrica, com controle de temperatura por meio de um termômetro comum. Eram pesados e colocados $30 \mathrm{ml}$ de grão inteiro na pipoqueira, quando atingia a temperatura de $280^{\circ} \mathrm{C}$ e o pipocamento se completava no período de quatro minutos e a capacidade de expansão era obtida pela relação entre o volume de pipoca medido em proveta de $1000 \mathrm{ml}$ e o peso dos 30ml de grão.

O programa computacional foi desenvolvido na linguagem de programação Visual Basic 4.0, para ambiente Windows. Os valores utilizados para os fatores de debulha $\left(\mathrm{k}_{\mathrm{T}}\right)$ foram ajustados por tentativa e erro, para cada variedade, até se ter um erro mínimo na determinação da eficiência de separação.

\section{RESULTADOS E DISCUSSÃO}

\section{Análise do efeito da trilha na qualidade do milho-pipoca}

Na Tabela 1 são apresentadas as médias da capacidade de expansão e a umidade dos grãos, determinados nos testes de trilha, realizados com as variedades Zélia e CMS-43. Procurou-se pipocar o milho-pipoca quando ele atingia a umidade próxima a $12 \%$ b.u., buscando-se atingir a umidade média em que o produto é geralmente comercializado e considerado ideal.
Tabela 1. Médias da capacidade de expansão em função da rotação do cilindro trilhador, e umidade

\begin{tabular}{lcccc}
\hline & \multicolumn{2}{c}{ Zélia } & \multicolumn{2}{c}{ CMS-43 } \\
\hline & $\begin{array}{c}\text { Capacidade } \\
\text { de expansão } \\
\left(\mathrm{ml.g}^{-1}\right)\end{array}$ & $\begin{array}{c}\text { Umidade } \\
(\% \text { b.u. })\end{array}$ & $\begin{array}{c}\text { Capacidade de } \\
\text { expansão } \\
\left(\mathrm{ml}^{-1}\right)^{-1}\end{array}$ & $\begin{array}{c}\text { Umidade } \\
(\% \text { b.u. })\end{array}$ \\
\hline Manual & 28,21 & 12,00 & 24,94 & 12,00 \\
500rpm & 28,63 & 12,13 & 22,85 & 12,63 \\
600rpm & 30,29 & 11,77 & 20,70 & 12,40 \\
700rpm & 29,62 & 12,07 & 21,53 & 12,67 \\
Média & 29,19 & 11,99 & 22,51 & 12,43 \\
\hline
\end{tabular}

$\mathrm{Na}$ Tabela 2 é apresentada a análise de variância dos dados da capacidade de expansão, mostrando que houve diferença significativa entre as variedades, ou seja, a diferença entre as capacidades de expansão ocorre, provavelmente, devido à diferença entre as características biológicas e as condições de colheita de cada variedade, e não pela diferença entre as rotações do cilindro trilhador. Houve diferença significativa na interação, mostrando que os fatores variedade e rotação não atuam independentemente, existindo o efeito da rotação entre cada variedade, isto é, as rotações tiveram influências distintas dentro de cada variedade, o que levou à necessidade de se estudar os fatores, de maneira isolada (Tabelas 3 e 4).

Tabela 2. Análise de variância dos dados de capacidade de expansão

\begin{tabular}{lcccc}
\hline FV & GL & SQ & QM & F \\
\hline Efeito da variedade (V) & 1 & 267,91 & 267,91 & $123,22 * *$ \\
Efeito da rotação (R) & 3 & 4,40 & 1,47 & 0,67 \\
Efeito V x R & 3 & 69,10 & 23,03 & $10,59 * *$ \\
\hline Tratamento & 7 & 306,62 & - & - \\
Resíduo & 16 & 34,79 & 2,17 & - \\
\hline Total & 23 & 341,41 & & \\
\hline ** Significativo a 1\% de probabilidade, pelo teste F & & &
\end{tabular}

A análise de variância, apresentada na Tabela 3, mostra que houve diferença significativa entre as variedades, e que a variedade Zélia foi a que apresentou maior capacidade de expansão para todas as rotações, quando comparadas as média de ambas as variedades (Tabela 1).

Tabela 3. Desdobramento da interação variedade x rotação com variedade dentro de rotação para a capacidade de expansão

\begin{tabular}{lcccc}
\hline FV & GL & SQ & QM & F \\
\hline Rotação & 3 & - & - & - \\
$\operatorname{Var}($ R0) & 1 & 16,04 & 16,04 & $7,38^{*}$ \\
$\operatorname{Var}(\mathrm{R} 1)$ & 1 & 50,10 & 50,10 & $23,05^{* *}$ \\
$\operatorname{Var}(\mathrm{R} 2)$ & 1 & 137,80 & 137,80 & $63,38^{* *}$ \\
$\operatorname{Var}(\mathrm{R} 3)$ & 1 & 98,28 & 98,28 & $45,20^{* *}$ \\
Resíduo & 16 & 34,79 & 2,17 & - \\
\hline Total & 23 & & &
\end{tabular}

* Significativo a $5 \%$ de probabilidade, pelo teste $\mathrm{F}$

** Significativo a $1 \%$ de probabilidade, pelo teste $\mathrm{F}$

Houve diferença significativa das rotações dentro da variedade CMS-43, mas o mesmo não aconteceu para a variedade Zélia, conforme observado na análise de variância 
apresentada na Tabela 4; portanto, a capacidade de expansão da variedade CMS-43 foi influenciada pela velocidade do cilindro trilhador, tendo cada velocidade influência distinta no valor da capacidade de expansão, significando que existe uma velocidade de rotação do cilindro trilhador entre 500 e 700rpm o que, possivelmente, proporcionará maior capacidade de expansão da variedade CMS-43.

Tabela 4. Desdobramento da interação com rotação dentro de variedade para a capacidade de expansão

\begin{tabular}{lcccc}
\hline FV & GL & SQ & QM & F \\
\hline Var (R) & 1 & - & - & - \\
Rot (V1) & 3 & 8,03 & 2,68 & 1,23 \\
Rot (V2) & 3 & 30,68 & 10,23 & $4,70 *$ \\
Resíduo & 16 & 34,79 & 2,17 & - \\
\hline Total & 23 & & & \\
\hline * Significativo a 5\% de probabilidade, pelo teste F & & \\
Var(R) - estudo da influência das variedades dentro das rotações & & \\
Rot(V) - estudo da influência das rotaçōes dentro das variedades.
\end{tabular}

Na Tabela 5 são apresentadas as médias dos valores da porcentagem de injúria e a umidade dos grãos determinados nos testes de trilha, realizados com as variedades Zélia e CMS-43, em função da velocidade do cilindro trilhador.

Tabela 5. Média da porcentagem de injúria em função da rotação do cilindro trilhador e umidade

\begin{tabular}{lcccc}
\hline & \multicolumn{2}{c}{ ZÉLIA } & \multicolumn{2}{c}{ CMS-43 } \\
\hline & $\begin{array}{c}\text { Porcentagem } \\
\text { de injúria }\end{array}$ & $\begin{array}{c}\text { Umidade } \\
(\% \text { b.u. })\end{array}$ & $\begin{array}{c}\text { Porcentagem } \\
\text { de injúria }\end{array}$ & $\begin{array}{c}\text { Umidade } \\
(\% \text { b.u. })\end{array}$ \\
\hline Manual & 0,00 & 12,00 & 0,00 & 12,00 \\
500rpm & 1,59 & 12,13 & 0,90 & 12,63 \\
600rpm & 1,18 & 11,77 & 1,37 & 12,40 \\
700rpm & 1,18 & 12,07 & 0,73 & 12,67 \\
\hline Média & 1,32 & 11,99 & 1,00 & 12,43 \\
\hline
\end{tabular}

Na Tabela 6 é apresentada a análise de variância dos dados da porcentagem de injúria ocasionada aos grãos; esta análise mostra, também, que houve diferença significativa entre as variedades, ou seja, a diferença entre as porcentagens de injúria é devida, provavelmente, à diferença entre as características biológicas e as condições de colheita de cada variedade demonstrando, assim, ser mais susceptível aos danos, que outra. Há, também, diferença significativa entre as rotações do cilindro trilhador para cada variedade, isto é, a diferença entre a porcentagem de injúria foi ocasionada pela diferença de velocidade de rotação do cilindro trilhador. Esta análise mostra, ainda, que houve diferença significativa na interação dos fatores

Tabela 6. Análise de variância para a porcentagem de injúria

\begin{tabular}{lcccc}
\hline FV & GL & SQ & QM & F \\
\hline Efeito da variedade & 1 & 0,34 & 0,34 & $6,56^{*}$ \\
Efeito da rotação & 3 & 6,42 & 2,14 & $41,17 * *$ \\
Efeito V x R & 3 & 1,56 & 0,52 & $9,99 * *$ \\
Tratamento & 7 & 7,48 & - & - \\
Resíduo & 16 & 0,83 & 0,05 & - \\
\hline Total & 23 & 8,31 & 0,36 & \\
\hline
\end{tabular}

* Significativo a $5 \%$ de probabilidade, pelo teste $\mathrm{F}$

** Significativo a $1 \%$ de probabilidade, pelo teste $\mathrm{F}$ variedade e rotação, estando os fatores relacionados, existindo o efeito da rotação entre cada variedade, o que levou ao estudo dos fatores, isoladamente (Tabelas 7 e 8).

A análise de variância apresentada na Tabela 7 mostra que existe diferença significativa entre as variedades para as rotações de 500 (R1) e 700 (R3) rpm, diferenças essas detectadas na comparação direta entre os valores das médias apresentadas na Tabela 5. A variedade Zélia foi a que apresentou maior porcentagem de injúria para ambas as rotações.

Por meio da análise de variância da Tabela 8 , observou-se que houve diferença significativa entre as rotações para as variedades CMS-43 e Zélia; portanto, existe velocidade de rotação do cilindro trilhador entre 500 e 700rpm que proporcionará, possivelmente, menor porcentagem de injúria para as duas variedades.

Tabela 7. Desdobramento da interação com variedade dentro de rotação para a porcentagem de injúria

\begin{tabular}{lcccc}
\hline CV & GL & SQ & QM & F \\
\hline Rotação & 3 & - & - & - \\
$\operatorname{Var}(\mathrm{R} 0)$ & 1 & 0,00 & 0,00 & 0,00 \\
$\operatorname{Var}(\mathrm{R} 1)$ & 1 & 0,71 & 0,71 & $13,59^{* *}$ \\
$\operatorname{Var}(\mathrm{R} 2)$ & 1 & 0,05 & 0,05 & 1,00 \\
$\operatorname{Var}(\mathrm{R} 3)$ & 1 & 0,31 & 0,31 & $5,93^{*}$ \\
Resíduo & 16 & 0,83 & 0,05 & - \\
\hline Total & 23 & & \\
\hline * Significativo a 5\% de probabilidade, pelo teste $\mathrm{F}$ &
\end{tabular}

** Significativo a $1 \%$ de probabilidade, pelo teste $\mathrm{F}$

Tabela 8. Desdobramento da interação com rotação dentro de variedade para a porcentagem de injúria

\begin{tabular}{lcccc}
\hline FV & GL & SQ & QM & F \\
\hline Variedade & 1 & - & - & - \\
Rot (V1) & 3 & 4,24 & 1,41 & $27,20^{* *}$ \\
Rot (V2) & 3 & 2,90 & 0,97 & $18,62^{* *}$ \\
Resíduo & 16 & 0,83 & 0,05 & - \\
\hline
\end{tabular}

Total

23

** Significativo a $1 \%$ de probabilidade, pelo teste $\mathrm{F}$

\section{Simulação da trilha}

São apresentados, nas Tabelas 9 e 10, os dados da análise de trilha e da simulação da separação do côncavo realizado no milho-pipoca, variedades Zélia e CMS-43, respectivamente.

Na Tabela 11 são apresentadas as características da máquina e das variedades, utilizadas como constantes do modelo e como parâmetros de entrada no programa computacional desenvolvido.

Com os dados determinados experimentalmente e os calculados apresentados nas Tabelas 9, 10 e 11, foi possível desenvolver-se um programa computacional para simulação do processo de trilha do milho-pipoca em uma colhedora combinada no campo. O modelo matemático implementado apresentou um erro relativo médio na determinação da eficiência de trilha de 2,79\% para a variedade Zélia e de 5,13\% para a CMS-43, apresentando o modelo, desta forma, um erro relativo médio, de $3,96 \%$. Os erros ocorridos no modelo foram ocasionados, possivelmente, por falta de precisão dos instrumentos utilizados na medição dos parâmetros experimentais e, também, por não 
Tabela 9. Dados da análise de trilha e simulação da separação do côncavo realizado no milho-pipoca, variedade Zélia, para uma velocidade da esteira do elevador de $1,00 \mathrm{~km} \cdot \mathrm{h}^{-1}$

\begin{tabular}{|c|c|c|c|c|c|c|c|c|c|}
\hline \multicolumn{10}{|c|}{ Rotações (rpm) } \\
\hline \multirow[t]{2}{*}{ Parâmetro } & \multicolumn{3}{|c|}{500} & \multicolumn{3}{|c|}{600} & \multicolumn{3}{|c|}{700} \\
\hline & $\mathrm{R} 1 *$ & $\mathrm{R} 2 * *$ & $\mathrm{R} 3 * * *$ & $\mathrm{R} 1$ & $\mathrm{R} 2$ & R3 & $\mathrm{R} 1$ & $\mathrm{R} 2$ & $\mathrm{R} 3$ \\
\hline Tempo de alimentação (s) & 49,31 & 42,01 & 46,41 & 41,64 & 48,01 & 49,9 & 45,73 & 50,44 & 49,07 \\
\hline Taxa de alimentação $\left(\mathrm{kg} \cdot \mathrm{s}^{-1}\right)$ & 0,232 & 0,213 & 0,213 & 0,218 & 0,210 & 0,256 & 0,207 & 0,191 & 0,224 \\
\hline Eficiência de separação calculada (\%) & 80,17 & 80,98 & 74,90 & 76,35 & 81,54 & 78,25 & 82,49 & 82,38 & 81,30 \\
\hline Eficiência de separação simulada (\%) & 79,60 & 79,53 & 80,02 & 80,02 & 80,02 & 79,65 & 79,58 & 79,65 & 79,69 \\
\hline Erro $(\%)$ & 0,71 & 1,64 & 6,34 & 2,06 & 4,05 & 2,27 & 3,03 & 1,83 & 3,21 \\
\hline Porcentagem de perda & 2,06 & 2,31 & 3,00 & 2,37 & 2,16 & 2,12 & 2,92 & 1,65 & 2,25 \\
\hline
\end{tabular}

Tabela 10. Dados da análise de trilha e simulação da separação do côncavo realizado no milho-pipoca, variedade CMS-43, para uma velocidade da esteira do elevador de $1,00 \mathrm{~km} \cdot \mathrm{h}^{-1}$

\begin{tabular}{|c|c|c|c|c|c|c|c|c|c|}
\hline \multirow{3}{*}{ Parâmetro } & \multicolumn{6}{|c|}{ Rotações (rpm) } & \multirow{2}{*}{\multicolumn{3}{|c|}{700}} \\
\hline & \multicolumn{3}{|c|}{500} & \multicolumn{3}{|c|}{600} & & & \\
\hline & $\mathrm{R} 1 *$ & $\mathrm{R} 2 * *$ & $\mathrm{R} 3 * * *$ & R1 & $\mathrm{R} 2$ & R3 & $\mathrm{R} 1$ & $\mathrm{R} 2$ & R3 \\
\hline Tempo de alimentação (s) & 47,87 & 50,19 & 48,87 & 48,38 & 50,93 & 51,77 & 52,13 & 40,40 & 46,61 \\
\hline Taxa de alimentação $(\mathrm{kg} / \mathrm{s})$ & 0,235 & 0,231 & 0,192 & 0,203 & 0,183 & 0,221 & 0,199 & 0,231 & 0,236 \\
\hline Eficiência de separação calculada (\%) & 78,72 & 77,07 & 74,75 & 76,44 & 90,15 & 81,69 & 79,80 & 84,43 & 85,47 \\
\hline Eficiência de separação simulada (\%) & 77,52 & 77,52 & 77,56 & 77,59 & 77,60 & 77,57 & 77,61 & 77,59 & 77,49 \\
\hline Erro $(\%)$ & 1,53 & 0,58 & 3,49 & 1,51 & 13,92 & 5,04 & 2,75 & 8,10 & 9,22 \\
\hline Porcentagem de perda & 1,51 & 1,55 & 4,12 & 2,66 & 1,01 & 1,26 & 1,74 & 0,61 & 0,53 \\
\hline
\end{tabular}

Tabela 11. Características da máquina e das variedades de milhopipoca utilizadas na realização dos testes e da simulação

\begin{tabular}{lc}
\hline Características & Valor \\
\hline Diâmetro do cilindro trilhador $(\mathrm{D})$ & $0,35 \mathrm{~m}$ \\
Comprimento do côncavo $(\mathrm{L})$ & $0,31 \mathrm{~m}$ \\
Largura do cilindro $(\mathrm{W})$ & $0,80 \mathrm{~m}$ \\
Velocidade da esteira que alimenta o cilindro $\left(\mathrm{V}_{0}\right)$ & $0,873 \mathrm{~m} / \mathrm{s}$ \\
Distância entre as barras circulares do côncavo $\left(\mathrm{a}_{1}\right)$ & $0,0178 \mathrm{~m}$ \\
Diâmetro das barras circulares do côncavo $\left(\mathrm{a}_{2}\right)$ & $0,0054 \mathrm{~m}$ \\
Distância entre as barras retangulares do côncavo $\left(\mathrm{b}_{1}\right)$ & $0,0425 \mathrm{~m}$ \\
Espessura das barras retangulares do côncavo $\left(\mathrm{b}_{2}\right)$ & $0,00642 \mathrm{~m}$ \\
\hline \multicolumn{1}{c}{ Para a variedade Zélia } & \\
\hline Densidade do material que não é grão $(\rho)$ & $15,26 \mathrm{~kg} / \mathrm{m}^{3}$ \\
Diâmetro equivalente $(\mathrm{dg})$ & $0,0062 \mathrm{~m}$ \\
Abertura de entrada entre o cilindro e o côncavo & $14,90 \mathrm{~mm}$ \\
Abertura de saída entre o cilindro e o côncavo & $7,65 \mathrm{~mm}$ \\
Fator de debulha $\left(\mathrm{k}_{\mathrm{t}}\right)$ & 0,0030 \\
Fator de correção $\left(\mathrm{k}_{\mathrm{m}}\right)$ & 0,3700 \\
\hline Para a variedade CMS-43 & \\
\hline Densidade do material que não é grão $(\rho)$ & $15,07 \mathrm{~kg} / \mathrm{m}^{3}$ \\
Diâmetro equivalente $(\mathrm{dg})$ & $0,00675 \mathrm{~m}$ \\
Abertura de entrada entre o cilindro e o côncavo & $17,08 \mathrm{~mm}$ \\
Abertura de saída entre o cilindro e o côncavo & $8,89 \mathrm{~mm}$ \\
Fator de debulha $\left(\mathrm{k}_{\mathrm{t}}\right)$ & 0,008 \\
Fator de correção $\left(\mathrm{k}_{\mathrm{m}}\right)$ & 0,0037 \\
\hline & \\
\hline
\end{tabular}

se conhecer com precisão o valor do fator de debulha; ainda assim, o modelo representou, com satisfatória precisão, os resultados experimentais, razão por que é considerado satisfatório para aplicações em engenharia.

A variedade Zélia apresentou menor perda para a rotação de 600rpm e a CMS-43 para a rotação de 700rpm, sendo que esta foi a que apresentou menor perda, dentre as duas variedades. Os testes foram realizados em laboratório, com o objetivo de se determinar a capacidade de separação do côncavo; não estão incluídas nas perdas a pré-colheita e as na plataforma de corte.

Para ambas as variedades, a melhor eficiência calculada, dentre as três rotações, foi detectada na rotação de 700rpm e a melhor eficiência simulada foi verificada na rotação de 600rpm, que mostra a possível existência de uma rotação intermediária que, possivelmente, proporcionará uma eficiência próximo da ideal.

\section{CONCLUSÕES}

As análises e as interpretações dos resultados da simulação e dos efeitos da máquina na qualidade do milho-pipoca, nas condições em que foi conduzido o trabalho, permitiram chegar-se às seguintes conclusões:

1. A variedade Zélia foi a que apresentou melhor capacidade de expansão, para todas as rotações, quando comparada com a CMS-43; a rotação teve influência somente para a variedade CMS-43. Houve diferença significativa na porcentagem de injúria entre as variedades, em que a Zélia apresentou a maior porcentagem para as rotações de 500 e 700rpm, não existindo diferença significativa na outra rotação. 
2. A variedade Zélia apresentou menor perda para a rotação de 600rpm e a CMS-43 para a de 700rpm, sendo que esta foi a que apresentou menor perda, dentre as duas.

3. O modelo computacional desenvolvido apresentou um erro relativo médio na determinação da eficiência de trilha, de $3,96 \%$, considerado satisfatório para aplicações em engenharia.

\section{REFERÊNCIAS BIBLIOGRÁFICAS}

CARVALHO, N.M.; NAKAGAWA, J. Injúria mecânica. Sementes; Ciência, Tecnologia e Produção. Campinas, Fundação Cargill, 1980. p.223-34.

COOPERCITRUS. Miho de pipoca. Cultura tem tudo para expandir-se. Informativo da Cooperativa dos Cafeicultores e Citricultores de São Paulo, v.II, n.78, p.08-11,1993.

HUYNH, V.M.; POWELL, T.; SIDDALL, J.N. Threshing and separating Process - A Mathematical Model. Transactions of the Americam Society of Agricultural Engineers, v.25, n.1, p.65-73, 1982.

NORRIS, E.R. \& WALL, G.L. Effect of concave design factors on cylinder-concave performance in corn. Canadian Agricultural Engineering, v.28 n.2, p.97-99, 1986.
KEPNER, R.A.; BAINER, R.; BARGER, E.L. Principles of farm machinery. $2^{\text {nd }}$ ed. Westport, Connecticut, AVI Publishing Company, 1972. 486p.

SILVA, W.J. Estudo amplia pesquisa do milho. Jornal da UNICAMP, Campinas, maio, 1993, p.8.

WHITE, G.M.; ROSS, I.J.; PONELEIT, C. G. Influence of drying parameters on the expansion volume of popcorn. Transactions of the Americam Society of Agricultural Engineers v.23, n.5, p.1272-1276, 1980.

WHITE, G.M.; ROSS, I.J.; PONELEIT, C.G. Fully-exposed drying of popcorn. Transactions of the Americam Society of Agricultural Engineers v.24, n.2, p.466-468, 1981.

WHITE, G.M.; ROSS, I.J.; PONELEIT, C.G. Stress crack development in popcorn as influenced by drying and rehydration processes. Transactions of the Americam Society of Agricultural Engineers v.25, n.3, p.768-772, 1982.

ZINSLY, J.R.; MACHADO, J.A. Milho de pipoca. In: FUNDAÇÃO CARGILL. Melhoramento e produção do milho no Brasil, coord. por E. Paterniani. Piracicaba: ESALQ, p.339-347, 1978. 